\title{
Classifying sarcopenia: using median value or cut-off values?
}

\author{
Onur Bas ${ }^{1}\left[{ }^{1} \cdot\right.$ Omer Dizdar ${ }^{1}$
}

Received: 6 April 2019 / Accepted: 16 April 2019 / Published online: 25 April 2019

(c) Springer Science+Business Media, LLC, part of Springer Nature 2019

We read with great interest the article by Eun Jin Song et al. published in Breast Cancer Research and Treatment entitled "Prognostic impact of skeletal muscle volume in breast cancer." The authors showed that sarcopenia had prognostic impact in breast cancer. The authors suggested that muscle volume at L3 vertebra level obtained by computer tomography can be used to determine sarcopenia. They used median muscle volume to dichotomize patients as sarcopenic or not. Although sarcopenia has an prognostic impact in breast cancer, using median values is not the best way to determine sarcopenia. Median values are descriptive measures to analyze target population but can be misleading for diagnostic purposes. When you classify according to the median, you naturally set the upper limit of sarcopenia as $50 \%$ and some sarcopenic patients can be classified as "normal," or vice versa. We propose that using common pre-specified cut-off values to define sarcopenia might be more useful and better feasible than median values. Previously, European Sarcopenia consensus [1] and sarcopenia definition for American population by Derstine et al. [2] determined cut-off values for sarcopenia for both European and American population. In Korean population, it was defined as $49 \mathrm{~cm}^{2} \mathrm{~m}^{-2}$ for men and $31 \mathrm{~cm}^{2} \mathrm{~m}^{-2}$ for women on L3 vertebra level muscle volume by KHANES study (Korean population, based on the Korea National Health and Nutrition Examination Study) [3]. Using cut-off values to define sarcopenia also provides comparability with other studies and reference for further studies.

\section{Compliance with ethical standards}

Conflict of interest All authors declare that they have no conflict of interest.

Ethical approval This article does not contain any studies with human participants or animals performed by any of the authors. This article complies with the ethical rules applicable for this journal.

Informed consent This letter does not contain any studies with human participants or animals performed by any of the authors.

\section{References}

1. Cruz-Jentoft AJ, Bahat G, Bauer J et al (2019) Sarcopenia: revised European consensus on definition and diagnosis. Age Ageing 48(1):16-31. https://doi.org/10.1093/ageing/afy169

2. Derstine BA, Holcombe SA, Ross BE, Wang NC, Su GL, Wang SC (2018) Skeletal muscle cutoff values for sarcopenia diagnosis using T10 to L5 measurements in a healthy US population. Sci Rep 8(1):11369. https://doi.org/10.1038/s41598-018-29825-5

3. Lee JS, Kim YS, Kim EY, Jin W (2018) Prognostic significance of CT-determined sarcopenia in patients with advanced gastric cancer. PLoS ONE 13(8):e0202700. https://doi.org/10.1371/journ al.pone. 0202700

Publisher's Note Springer Nature remains neutral with regard to jurisdictional claims in published maps and institutional affiliations.

This letter to the editor refers to the article available at doi:https:// doi.org/10.1007/s10549-018-4915-7.

Onur Bas

onur6191@ hotmail.com

1 Division of Medical Oncology, Department of Internal

Medicine, Faculty of Medicine, Hacettepe University,

06100 Sihhiye, Ankara, Turkey 